\title{
EVALUASI PERENCANAAN OBAT DAN PERBEKALAN FARMASI DI DEPO PUSAT JANTUNG TERPADU R.S.U.P HAJI ADAM MALIK MEDAN
}

\author{
Ismedsyah ${ }^{1}$ dan Sri Rahayu ${ }^{2}$ \\ 1,2Jurusan Farmasi Poltekkes Kemenkes Medan Indonesia RSUP Haji Adam Malik Medan \\ Email: ismedsyah@gmail.com
}

\begin{abstract}
ABSTRAK
Perencanaan merupakan kegiatan menetapkan jenis dan jumlah obat sesuai kebutuhan. Perencanaan lemah ditandai terjadinya kekosongan atau penumpukan obat. Tujuan penelitian ini adalah yaitu mengevaluasi perencanaan obat dan perbekalan farmasi di Depo PJT RSUP HAM Medan tahun 2016-2017.Jenis penelitian yang dilakukan adalah penelitian non-eksperimental dengan pendekatan deskriptif. Pengumpulan data yang digunakan dalam penelitian ini adalah pengamatan observasi. Observasi yang dimaksud adalah menganalisis catatan perencanaan di Depo PJT RSUP HAM Medan tahun 2016-2017. Hasil penelitian menunjukkan bahwa ketersediaan dana pada tahun 2016 sebesar $102 \%$ dan 2017 sebesar 101\%, ini sudah memenuhi nilai standar yang telah ditetapkan yaitu $100 \%$. Persentase penyerapan terhadap dana yang disediakan pada tahun 2016 sebesar $98 \%$ dan 2017 sebesar $99 \%$. Persentase penyimpangan perencanaan yang didapat pada tahun 2016 adalah sebesar 8,1\% dan pada tahun 2017 adalah sebesar 4,7\%. Kesimpulan dari penelitian ini menunjukkan persentase ketersediaan dana pada tahun 2016 telah memenuhi nilai standar yang telah ditetapkan dalam Peraturan Menteri Kesehatan Republik Indonesia Nomor 72 tahun 2016. Penyimpangan perencanaan di Depo PJT RSUP HAM Medan tahun 2016 dan 2017 masih didalam batas nilai batas penyimpangan perencanaan yaitu antara $20-30 \%$.
\end{abstract}

Kata Kunci : Perencanaan, Obat, Evaluasi, Penyimpangan Perencanaan

\begin{abstract}
Planning is an activity to determine the type and amount of medicine as needed. Weak planning is marked by the occurrence of emptiness or accumulation of drugs. The purpose of this study is to evaluate the medicine planning and pharmacy supplies at Depo PJT RSUP HAM Medan period 2016-2017. The method of research is non-experimental research with a descriptive approach. Data collection used in this study is observations. Observations in question is analyzed records at Depo PJT RSUP HAM Medan 2016-2017. Research results show that he availability of funds in 2016 amounted to $102 \%$ and 2017 amounted to $101 \%$, this has met the predetermined standard value of $100 \%$. The percentage of absorption of funds provided in 2016 was $98 \%$ and 2017 was $4.7 \%$. Conclusion of this research show percentage availability funds in 2016 have been meet value standards that have been set in Regulation of the Minister of Health of Republic of Indonesia Number 72 of 2016. Deviations in Depo PJT planning RSUP Human Terrain 2016 and 2017 is still within the limit values limit deviation planning that is between $20-30 \%$.
\end{abstract}

Keywords : Planning, Medicine, Evaluation, Planning Deviation 


\section{PENDAHULUAN}

Menurut Undang-undang $\mathrm{RI}$ Nomor 44 Tahun 2009 tentang Rumah Sakit yang dimaksud dengan Rumah Sakit adalah institusi pelayanan kesehatan yang memberikan pelayanan kesehatan perorangan secara paripurna yang menyediakan pelayanan rawat inap, rawat jalan, dan gawat darurat. Untuk melaksanakan kegiatan Rumah Sakit dibutuhkan beberapa standar diantaranya adalah Standar Pelayanan Kefarmasian. Esensi dari keberadaan Standar Pelayanan Kefarmasian merupakan tolak ukur yang dipergunakan sebagai pedoman bagi tenaga kefarmasian dalam menyelenggarakan pelayanan kefarmasian ${ }^{1}$. Secara fungsional implementasi dari Standar Pelayanan Kefarmasian dilaksanakan oleh Instalasi Farmasi. Pelayanan Kefarmasian yang diselenggarakan oleh Instalasi Farmasi meliputi pengelolaan Obat dan Perbekalan Farmasi serta pelayanan farmasi klinik.

Pada Rumah Sakit Umum Pusat Haji Adam Malik Medan (RSUP-HAM Medan) bahwa pengelolaan Obat dan Perbekalan Farmasi diselenggarakan oleh Instalasi Farmasi. Namun karena aktivitas pelayanan pada Instalasi Farmasi sangat banyak, maka pengelolaan Obat dan Perbekalan Farmasi diselenggarakan juga di Depo Farmasi.

Depo Farmasi dipimpin oleh seorang kepala yang berada di bawah dan bertanggungjawab langsung kepada
Kepala Instalasi Farmasi RSUP-HAM Medan dan mempunyai tugas membantu Kepala Instalasi Farmasi dalam hal mengkoordinasi, membina, melaksanakan perencanaan, penerimaan, penyimpanan dan pendistribusian perbekalan farmasi untuk kebutuhan pasien. Depo Farmasi merupakan unit pelayanan langsung Obat dan Perbekalan Farmasi yang berada di ruang perawatan, unit gawat darurat (UGD), intensive care unit (ICU), instalasi bedah sentral (IBS) dan Pusat Jantung Terpadu (PJT) untuk persediaan sesuai dengan kebutuhan unit tersebut.

Pada depo farmasi PJT banyak Obat dan Perbekalan Farmasi yang harus dikelola dengan baik dan benar untuk memenuhi kebutuhan pasien. Satu bagian diantara bagian yang harus dikelola dengan baik dan benar yaitu perencanaan yang mengacu kepada indikator perencanaan. Untuk mengetahui apakah selama ini dilakukan perencanaan pada depo farmasi PJT RSUP-HAM Medan mengacu kepada indikator perencanaan, maka penulis tertarik untuk melakukan penelitian pada depo tersebut dengan judul "Evaluasi Perencanaan Obat dan Perbekalan Farmasi di Depo PJT RSUPHAM Medan Tahun 2016-2017“.

\section{SEDIAAN FARMASI}

Menurut Undang-undang No.36 Tahun 2009 tentang Kesehatan bahwa sediaan farmasi adalah obat, bahan obat, obat tradisional, dan kosmetika. 
Sedangkan obat adalah bahan atau paduan bahan, termasuk produk biologi yang digunakan untuk mempengaruhi atau menyelidiki sistem fisiologi atau keadaan patologi dalam rangka penetapan diagnosis, pencegahan, penyembuhan, pemulihan, peningkatan kesehatan dan kontrasepsi untuk manusia.

Obat adalah zat yang digunakan untuk diagnosis, mengurangi rasa sakit, serta mengobati atau mencegah penyakit pada manusia atau hewan ${ }^{3}$. Sedangkan, menurut Undang-undang No.36 Tahun 2009 tentang kesehatan pengertian obat adalah bahan atau paduan bahan, termasuk produk biologi yang digunakan untuk mempengaruhi atau menyelidiki sistem fisiologi atau keadaan patologi dalam rangka penetapan diagnosis, pencegahan, penyembuhan, pemulihan, peningkatan kesehatan dan kontrasepsi, untuk manusia.

Obat yang dibutuhkan dalam melayani pasien pada PJT berjumlah 281 jenis.Jenis obat yang digunakan, diantaranya adalah, lovenox, sefepim, clopidogrel, verapamil dan valsartan.

\section{ALAT KESEHATAN DAN BAHAN MEDIS HABIS PAKAI (BMHP)}

Alat kesehatan adalah instumen, apparatus, mesin dan/atau implant yang tidak mengandung obat yang digunakan untuk mencegah, mendiagnosis, menyembuhkan dan meringankan penyakit, merawat orang sakit, memulihkan kesehatan pada manusia, dan/atau membentuk struktur dan memperbaiki fungsi tubuh ${ }^{4}$.

Alat kesehatan (Alkes) yang dibutuhkan dalam melayani pasien pada PJT berjumlah 40 jenis.Jenis alat kesehatan yang digunakan,diantaranya adalah Azule, Combo, Firebird, Implant PermanentPace Maker (PPM) dan balon sapphir.

Bahan Medis Habis Pakai (BMHP) adalah alat kesehatan yang ditujukan untuk penggunaan sekali pakai (single use) yang daftar produknya diatur dalam peraturan perundang-undangan ${ }^{4}$. BMHP yang dibutuhkan dalam melayani pasien pada PJT berjumlah 299 jenis.Jenis BMHPyang digunakan, diantaranya adalah Introducer Sheat Femoral $7 \mathrm{fr}$, Manifold, Guidewire 0,35 (180), Amplatzer Guidewire 0.35 (260), Asahi rinato.

\section{INDIKATOR PERENCANAAN OBAT}

Indikator yang digunakan dalam perencanaan obat adalah :

a. Persentase dana

Yaitu dana yang tersedia dibanding kebutuhan dana yang sesungguhnya. Nilai standar persentase dana yang tersedia adalah $100 \%$.

b. Penyimpangan perencanaan

Yaitu jumlah jenis obat dalam perencanaan dan jumlah jenis obat dalam kenyataan pakai. Nilai standar batas penyimpangan perencanaan adalah $20-30 \%$. 


\section{METODE PENELITIAN}

Penelitian ini adalah penelitian noneksperimental dengan pendekatan deskriptif, yaitu suatu metode yang memberikan gambaran atau keadaan objek yang diteliti berdasarkan data yang dikumpulkan kemudian di analisis oleh penulis sehingga dapat diambil keputusan dan kesimpulan yang tepat. Pada penelitian ini akan mengevaluasi perencanaan Obat dan Perbekalan Farmasi di Depo PJT RSUP-HAM Medan tahun 2016-2017.

\section{Populasi}

Populasi yang digunakan dalam penelitian ini adalah seluruh data perencanaan Obat dan Perbekalan Farmasi di Depo PJT RSUP-HAM Medan tahun 2016-2017.

\section{Sampel}

Teknik yang digunakan dalam penelitian ini adalah teknik sampel jenuh. Teknik sampel jenuh adalah teknik pengambilan sampel apabila semua populasi digunakan sebagai sampel ${ }^{5}$. Dalam penelitian ini sampel yang digunakan adalah seluruh data perencanaan Obat dan Perbekalan Farmasi di Depo PJT RSUP-HAM Medan tahun 2016-2017.

\section{Alat-alat}

Alat yang akan digunakan pada penelitian ini adalah berupa alat tulis, kertas, kalkulator, flashdisk dan kamera.

\section{Bahan-bahan}

Bahan yang digunakan adalah data perencanaan Obat dan Perbekalan Farmasi di Depo PJT RSUP-HAM Medan Tahun 2016-2017.

\section{Jenis data}

Pengambilan data dari penelitian ini adalah secara retrospektif dan prospektif yang didasarkan pada dokumen perencanaan Obat dan Perbekalan Farmasi dan wawancara di Depo PJT RSUP-HAM Medan. Data yang dikumpulkan berupa data primer dan data sekunder. Data primer yaitu data yang diperoleh melalui wawancara dengan 4 responden yang terdiri dari Kepala Instalasi Farmasi, Kepala Gudang, Kepala Bagian Perencanaan dan Kepala Depo PJT RSUP-HAM. Data sekunder yaitu data yang diperoleh dari laporan atau catatan yang ada di Depo PJT RSUPHAM Medan tahun 2016-2017 berupa laporan jenis yang digunakan, laporan jumlah pemakaian dan laporan harga Obat dan Perbekalan Farmasi.

\section{Pengumpulan data}

Cara pengumpulan data yang digunakan dalam penelitian ini adalah pengamatan observasi. Observasi yang dimaksud adalah menganalisis catatan perencanaan di Depo PJT RSUP-HAM Medan tahun 2016-2017. 


\section{Prosedur Kerja}

Permohonan Izin Kerjasama

Perizinan dilakukan dengan mengusulkan atau memasukkan surat permohonan izin penelitian ke R.S.U.P HAM Medan

Pembuatan Pedoman Wawancara

Pembuatan pedoman wawancara dilakukan dengan cara menyusun pertanyaan dan melampirkan data terkait perencanaan Obat dan Perbekalan Farmasi oleh Kepala Instalasi Farmasi, Kepala Bagian Perencanaan, Kepala Depo PJT dan Kepala Bagian Gudang R.S.U.P HAM Medan

\section{Pengambilan Data}

Pengambilan data diambil melalui proses perizinan dari Kepala Depo PJT terkait perencanaan dana di Depo PJT tahun 2016-2017 dan terkait jumlah obat dan sediaan farmasi yang direncanakan dan yang dikeluarkan dari Depo PJT R.S.U.P HAM Medan Tahun 2016-2017

\section{Pengolahan dan Analisis Data}

Data yang diperoleh diolah dan disajikan dalam bentuk table persentase berdasarkan indicator perencanaan obat dan perbekalan farmasi yaitu perencanaan dana dan penyimpangan perencanaan di Depo PJT R.S.U.P HAM Medan Tahun 2016-2017

\section{Pengolahan Data}

Data yang diperoleh diolah dan disajikan dalam bentuk tabel persentase berdasarkan indikator perencanaan Obat dan Perbekalan Farmasi di Depo PJT RSUP-HAM Medan Tahun 2016-2017.

\section{Analisis Data}

Analisis data adalah dalam penelitian pendekatan deksriptif, dilakukan pada saat data berlangsung, dan setelah selesai pengumpulan data dalam periode tertentu.

\section{HASIL DAN PEMBAHASAN}

Quick dkk (2012) menyebutkan bahwa siklus pengelolaan obat meliputi empat fungsi dasar, yaitu seleksi (selection), perencanaan dan pengadaan (procurement), distribusi (distribution), dan penggunaan (use) yang memerlukan dukungan dari perencanaan dan administrasi (planning and administration), manajemen organisasi (organization), pengelolaan informasi (information management) dan pengembangan sumber daya manusia (human resources management) yang ada di dalamnya.

Kemudian jika dibuat dalam bentuk siklus manajemen obat maka harus didukung oleh faktor-faktor pendukung manajemen (management support) yang meliputi organisasi, administrasi, keuangan, Sistem Informasi Manajemen (SIM) dan sumber daya manusia ${ }^{6}$.

\section{Persentase Dana}

Persentase ketersediaan dana adalah perbandingan antara dana yang disediakan dengan total dana yang 
dibutuhkan dalam perencanaan obat kemudian dikalikan seratus persen. Berdasarkan pengamatan dokumen tahun 2016 total dana yang dibutuhkan untuk mengadakan 1386 jenis obat dan Perbekalan Farmasi sebesar Rp. 14.116.502.956 dan dana yang disediakan Rp. 14.398.833.015 berarti persentase dana untuk belanja obat dan Perbekalan Farmasi di Depo PJT R.S.U.P HAM Medan tahun 2016 sebesar 102\%.
Berdasarkan pengamatan dokumen tahun 2017 total dana yang dibutuhkan untuk mengadakan obat dan Perbekalan Farmasi sebesar Rp. 23.522.644.764 sedangkan dana yang disediakan sebesar Rp.23.757.871.211. dengan demikian maka persentase ketersediaan dana perencanaan obat dan Perbekalan Farmasi di Depo PJT R.S.U.P HAM Medan tahun 2017 sebesar 101\%.

Tabel 4.1 Persentase Dana Belanja Obat dan Perbekalan Farmasi di Depo PJT R.S.U.P HAM Medan Tahun 2016 dan 2017

\begin{tabular}{lcccccc}
\hline & & Nilai & \multicolumn{2}{l}{ Dana Belanja Obat dan Perbekalan Farmasi } \\
No. & Kategori & Standar & & & \\
\cline { 3 - 6 } & & $\%$ & 2016 & $\%$ & 2017 & $\%$ \\
\hline 1. & Kebutuhan & \multirow{2}{*}{100} & 14.116 .502 .956 & & 23.522 .644 .764 & \multirow{2}{*}{101} \\
2. & Ketersediaan & & 14.398 .833 .015 & & 23.757 .871 .211 & 101 \\
\hline
\end{tabular}

Jika dibandingkan dengan nilai standar, maka persentase dana perencanaan obat dan Perbekalan Farmasi pada tahun 2016-2017 di Depo PJT R.S.U.P HAM adalah memenuhi standar karena masih dalam batas toleransi nilai standar yang telah ditetapkan yaitu sebesar 100\%. Dana yang cukup sangat menentukan ketersediaan dan keterjangkauan obat dan Perbekalan Farmasi oleh masyarakat. Ketersediaan dana untuk pengadaan obat dan Perbekalan Farmasi yang sesuai dengan kebutuhan akan mencapai terlaksananya penggunaan obat yang rasional serta akan meningkatkan mutu pelayanan kesehatan. Sedangkan dengan adanya persentase dana berlebih mengindikasikan bahwa sumber daya manusia yang melakukan proses perhitungan dan perencanaan kebutuhan anggaran untuk Depo PJT R.S.U.P HAM masih kurang trampil sehingga perlu ditingkatkan ketrampilannya melalui pelatihan.

Perencanaan obat merupakan satu tahap awal yang penting dalam menentukan keberhasilan tahap selanjutnya, sebab tahap perencanaan berguna untuk menyesuaikan antara kebutuhan pengadaan dengan dana yang tersedia untuk menunjang pelayanan 
kesehatan di rumah sakit. Perencanaan obat sangat mempengaruhi ketersediaan obat di rumah sakit, karena perencanaan bertujuan untuk menetapkan jenis dan jumlah obat sesuai dengan pola penyakit dan kebutuhan pelayanan kesehatan di rumah sakit agar tidak terjadi kekosongan maupun kelebihan obat.

Jika dibanding dengan penelitian evaluasi pengelolaan obat di Instalasi Farmasi RSUD Kabupaten Muna Tahun 2014 dilakukan oleh Sunandar Ihsan dkk (2014) dengan hasil persentase ketersediaan dana sebesar $104 \%$, maka penelitian Evaluasi Perencanaan Obat dan Perbekalan Farmasi di Depo PJT RSUP-HAM Medan Tahun 2016-2017 sedikit lebih baik hasilnya, sedangkan jika dibandingkan dengan penelitian evaluasi pengelolaan obat tahap perencanaan dan pengadaan pada era Jaminan Kesehatan Nasional di Instalasi Farmasi RSUD $X$ periode tahu 2016 oleh Chyntia Pramita Sari menghasilkan kesimpulan bahwa persentase ketersediaan dana sebesar 93,16\%, hasil ini diperoleh karena mengacu kepada data belanja pada tahun sebelummya dan tidak melihat adanya kenaikan jumlah kunjungan pasien serta kenaikan harga obat.

Berdasarkan teori Anshari (2009), halhal yang harus diperhatikan dalam perencanaan yaitu alokasi dana yang tersedia, harga per item obat dan penentuan berapa besar serta kapan pemesanan harus dilakukan. Apabila hal ini tidak sesuai, maka pengendalian perencanaan belum bisa dikatakan efektif. Efektif yang dimaksud ialah perencanaan yang mendapatkan jenis dan jumlah obat yang tepat dan sesuai dengan kebutuhan serta menghindari adanya kekosongan obat dan penumpukan obat.

\section{Penyimpangan Perencanaan}

Ketepatan perencanaan obat dan Perbekalan Farmasi dapat dilihat dengan menggunakan indikator penyimpangan perencanaan. Data dikumpulkan secara retrospektif dengan melihat dokumen perencanaan obat dan Perbekalan Farmasi dan dokumen penggunaan obat dan Perbekalan Farmasi di Depo PJT R.S.U.P HAM Medan tahun 2016-2017.

Penyimpangan perencanaan obat dan Perbekalan Farmasi diperoleh melalui pencocokan jumlah obat dan Perbekalan Farmasi yang direncanakan dalam dokumen perencanaan dengan jumlah item obat dan Perbekalan Farmasi yang digunakan dalam dokumen daftar penggunaan obat dan Perbekalan Farmasi di Depo PJT R.S.U.P HAM Medan tahun 2016-2017.

Diketahui bahwa jumlah jenis obat dan Perbekalan Farmasi yang direncanakan pada tahun 2016 adalah 2.276.122 jenis obat dan Perbekalan Farmasi serta yang digunakan selama tahun 2016 adalah sebanyak 2.091.722 jenis obat dan Perbekalan Farmasi atau yang tidak digunakan selama tahun 2016 adalah 184.400 jenis obat dan Perbekalan Farmasi. Berdasarkan hasil perhitungan 
bahwa penyimpangan perencanaan tahun 2016 sebesar $8,1 \%$. Bahwa jumlah jenis Obat dan Perbekalan Farmasi yang direncanakan pada tahun 2017 adalah 3.357.403 jenis dan yang digunakan adalah sebanyak 3.382 .250 jenis. Berdasarkan hasil perhitungan diperoleh penyimpangan perencanaan pada tahun 2017 adalah sebesar $4,7 \%$.

Tabel 4.2

Penyimpangan Perencanaan Obat dan Perbekalan Farmasi

di Depo PJT R.S.U.P HAM Medan Tahun 2016 dan 2017

\begin{tabular}{|c|c|c|c|c|c|c|}
\hline \multirow{2}{*}{ No. } & \multirow{2}{*}{ Kategori } & \multirow{2}{*}{$\begin{array}{c}\text { Nilai } \\
\text { Standar } \\
\%\end{array}$} & \multicolumn{4}{|c|}{ Penyimpangan Perencanaan } \\
\hline & & & 2016 & $\%$ & 2017 & $\%$ \\
\hline 1. & Perencanaan & \multirow{2}{*}{$20-30$} & 2.276 .122 & \multirow{2}{*}{8,1} & 3.357 .403 & \multirow{2}{*}{4,7} \\
\hline 2. & Penggunaan & & 2.091 .722 & & 3.382 .250 & \\
\hline
\end{tabular}

Idealnya, persentase nilai penyimpangan perencanaan menurut Depkes 2010 adalah 20-30\%. (Depkes, 2010). Nilai ini adalah batas toleransi penyimpangan antara jumlah Obat dan Perbekalan Farmasi yang direncanakan dengan jumlah Obat dan Perbekalan Farmasi yang digunakan dalam satu tahun.

Jika dibandingkan dengan nilai standar, maka presentase penyimpangan perencanaan obat di Depo PJT R.S.U.P HAM Medan jauh dibawah batas standar penyimpangan. Menurunnya persentase nilai penyimpangan perencanaan dari tahun 2016 ke tahun 2017 disebabkan terjadi penurunan perencanaan di tahun 2017 dibanding penggunaan sebaliknya terjadi peningkatan perencanaan di tahun 2016 dibanding penggunaan.
Hasil wawancara dengan kepala Depo PJT R.S.U.P HAM Medan, bahwa adanya penyimpangan perencanaan diakibatkan oleh proses peresepan oleh dokter selalu berubah-ubah, pola penyakit yang berubah-ubah, serta adanya ketidaksesuaian proses input data. Namun demikian menurut hasil wawancara dengan pegawai Depo PJT R.S.U.P HAM Medan, penyimpangan ini tidak begitu mempengaruhi proses pelayanan kesehatan khususnya pelayanan kefarmasian, adanya kesenjangan antara rencana dan obat yang terpakai tidak mengurangi kelancaran pelayanan kesehatan di Rumah Sakit.

Pada penelitian evaluasi pengelolaan obat di Instalasi Farmasi RSUD Kabupaten Muna Tahun 2014 dilakukan oleh Sunandar Ihsan dkk (2014) memberikan kesimpulan bahwa 
persentase penyimpangan perencanaan sebesar $\quad 9,15 \%$ hasil ini dibawah nilai standar yang telah ditetapkan yaitu sebesar 20 - $30 \%$. Hasil persentase 9,15 ini menunjukkan tidak ada penyimpangan perencanaan kebutuhan obat.

Perencanaan kebutuhan farmasi merupakan proses kegiatan dalam pemilihan jenis, jumlah dan harga perbekalan farmasi yang sesuai dengan kebutuhan dan anggaran, untuk menghindari kekosongan obat dengan menggunakan metode yang dapat dipertanggung jawabkan dan dasar-dasar perencanaan yang telah ditentukan antara lain konsumsi, epidmiologi, kombinasi metode konsumsi dan epidemiologi disesuaikan dengan anggaran yang tersedia ${ }^{7}$ Ketidakcukupan obat-obat disebabkan oleh berbagai faktor. Salah satu faktor yang sangat menentukan yaitu faktor perencanaan/perhitungan perkiraan kebutuhan obat yang belum tepat, belum efektif dan kurang efisien.

\section{KESIMPULAN}

Dari penelitian yang dilakukan dapat ditarik kesimpulan bahwa:

1. Persentase dana perencanaan belanja obat dan perbekalan farmasi di Depo PJT RSUP HAM Medan masih pada batas toleransi karena hanya sebesar $102 \%$ pada tahun 2016 dan sebesar 101\% pada tahun 2017

2. Penyimpangan perencanaan obat dan perbekalan farmasi di Depo PJT
RSUP HAM Medan masih dibawah standar Depkes 2010.

3. Perencanaan obat dan perbekalan farmasi di Depo PJT RSUP HAM Medan sesuai dengan standar Depkes 2010, dan kemungkinan tidak akan terjadi kekosongan obat serta tidak akan terjadi penumpukan obat dan perbekalan farmasi.

\section{DAFTAR PUSTAKA}

1. Kementerian Kesehatan Republik Indonesia. 2016. Peraturan Menteri Kesehatan Republik Indonesia Nomor 72 tahun 2016 tentang Standar Pelayanan Kefarmasian di Rumah Sakit. Jakarta: Kemenkes RI

2. Anonim. 2009. Undang undang Republik Indonesia No. 36 Tahun 2009 tentang Kesehatan

3. Ansel, C. Howard. 1985. Pengantar Bentuk Sediaan Farmasi, Edisi Keempat, Terjemahan : Farida Ibrahim. Jakarta: Universitas Indonesia Press

4. Departemen Kesehatan Republik Indonesia. 2010. Materi Pelatihan Manajemen Kefarmasian di Instalasi Farmasi di Kabupaten/Kota. Jakarta: Depkes RI

5. Sugiyono. 2014. Metode Penelitian Kuantitatif, Kualitatif, dan $R \& D$. Bandung: Penerbit Alfabeta.

6. Satibi. 2015. Manajemen Obat di Rumah Sakit (ed. Pertama). Yogyakarta: UGM-Press.

7. Herlambang S. 2016. Manajemen Pelayanan Kesehatan Rumah Sakit. Yogyakarta: Gosyen Publishing.

8. Anief, M. 2001. Manajemen Farmasi. Yogyakarta: Gadjah Mada Press

9. Anonim. 2002. Pedoman Perencanaan dan Pengelolaan Obat. Jakarta: Departemen Kesehatan Republik Indonesia

10. Anonim. 2009. Peraturan Pemerintah No. 51 Tahun 2009 tentang Pekerjaan Kefarmasian

11. Anonim. 2009. Undang undang Republik Indonesia No. 44 Tahun 2009 tentang Rumah Sakit 
12. Anshari, M. 2009. Aplikasi Managemen Pengelolaan Obat dan Makanan. Nuha Medika, Jakarta.

13. Ihsan S, Amir SA, Sahid M. Evaluasi Pengelolaan Obat di Instalasi Farmasi Rumah Sakit Umum Daerah Kabupaten Muna Tahun 2014.

14. Kusnadi, E. 2009. Analisis Produktivitas Terhadap Penyeimbangan Lintasan Unpublished Ungraduate Thesis, Program Studi Teknik Industri. Jakarta: Universitas Mercu Buana

15. Nofriana, E. 2011. Analisis $A B C$ dan VEN Terhadap Belanja Obat di RSUD Dr, Soedarso Pontianak Tahun 2010. Yogyakarta: Tesis Program Pasca Sarjana Manajemen dan Kebijakan Obat IImu Masyarakat

16. Sari P. C, 2016 Evaluasi Pengelolaan Obat Tahap Perencanaan dan Pengadaan pada Era Jaminan Kesehatan Nasional di Instalasi Farmasi RSUD X Periode Tahun 2016 : Program Studi Farmasi, Fakultas Kedokteran dan IImu Kesehatan Universitas Muhammadiyah Yogyakarta, Yogyakarta, Indonesia

17. Pudjaningsih, 1996. Pengembangan Indikator Efisiensi Pengelolaan Obat di Farmasi Rumah Sakit.Yogyakarta:Tesis Magister Manajemen Rumah Sakit Universitas Gadjah Mada

18. Quick, J.P., Rankin, J.R., Laing, R.O., O'Cornor, R.W. 2012. Managing Drug Supply, the selection, procurement, distribution and use of pharmaceutical, third edition. Conecticus, USA: Kumarin Press.

19. Siregar Ch.J.P., Amalia, L. 2004. "Teori \& Penerapan Farmasi Rumah Sakit". Jakarta: Penerbit Buku Kedokteran, EGC.

20. Sutarman. 2003. Perencanaan Persiapan Bahan Baku Dengan Model Backorder. Jakarta: Infomatek 